ENTREPRENEURSHIP AND SUSTAINABILITY ISSUES

ISSN 2345-0282 (online) http://jssidoi.org/jesi/

2019 Volume 6 Number 4 (June)

http://doi.org/10.9770/jesi.2019.6.4(20)

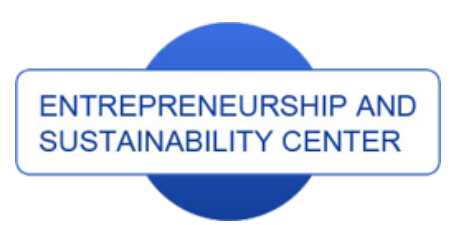

Publisher

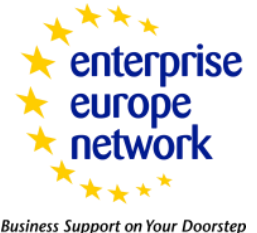

CASPA

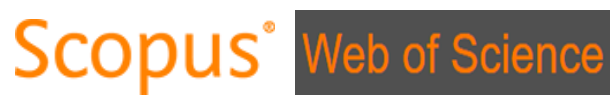

http://jssidoi.org/esc/home

Business Support on Your Doorstep

\title{
SUSTAINABLE DEVELOPMENT OF INDUSTRY 4.0: THE CASE OF HIGH-TECH PRODUCTS SYSTEM DESIGN*
}

\author{
Aleksandr M. Batkovskiy ${ }^{1}$, Aleksandr V. Leonov ${ }^{2}$, Aleksey Yu. Pronin ${ }^{3}$, \\ Elena G. Semenova ${ }^{4}$, Alena V. Fomina ${ }^{1}$, Victor M. Balashov ${ }^{5}$ \\ 1 JSC “Central Research Institute of Economy, Management and Information Systems "Electronics”, \\ 12 Kosmonavta Volkova Str., Moscow, 127299, Russian Federation \\ ${ }^{2}$ Moscow Aviation Institute (National Research University), \\ 4 Volokolamskoe shosse, Moscow, 125993, Russian Federation \\ ${ }^{3}$ MIREA - Russian Technological University, \\ 78 Vernadsky Avenue, Moscow, 119454, Russian Federation \\ ${ }^{4}$ Saint-Petersburg State University of Aerospace Instrumentation, \\ 67 Bolshaya Morskaia Str., Saint-Petersburg, 190000, Russian Federation \\ 5 JSC «Scientific and Production Enterpise "Radar MMS"» \\ 37A Novoselkovskaya Str., Saint-Petersburg, 197375, Russian Federation
}

E-mails: batkovskiy_a@instel.ru ; alex.clein51@yandex.ru ; pronin46@bk.ru ; egsemenova@mail.ru ; fomina.a@instel.ru , balashov-vm@radar-mms.com

Received 25 January 2019; accepted 10 April 2019; published 30 June 2019

\begin{abstract}
Modern production of high-tech products is characterized by the transition from the traditional design paradigm to the new paradigm of designing a holistic unified set of products. In this regard, the process of designing high-tech products needed to be allocated into a separate type - the system design. Its main methodological provisions are presented in the study. The result of the generalization was the developed system design model, which included the engineering design and process design stages, a method for evaluating the unification effectiveness, suitable for use at both intraspecific and trans-species levels, and an algorithm for the practical use of an integrated model and proposals for its use at the stages of creation of high-tech products. The use of the methodological toolkit for system design of high-tech products allows reducing the cost of their creation, production and operation significantly, as well as obtaining the structure of production with balanced efficiency and cost. The practical implementation of the proposed tools is possible at the stage of selecting design organizations. The developed toolkit is universal and can be used in all sectors of the economy.
\end{abstract}

Keywords: system design, Industry 4.0, high-tech products, production structure, sustainability, production model optimization.

\footnotetext{
* The study was carried out with the financial support of the Russian Foundation for Basic Research in the framework of the research project No. 18-00-00012 (18-00-0008) COMFI
} 


\section{ENTREPRENEURSHIP AND SUSTAINABILITY ISSUES}

ISSN 2345-0282 (online) http://jssidoi.org/jesi/

2019 Volume 6 Number 4 (June)

http://doi.org/10.9770/jesi.2019.6.4(20)

Reference to this paper should be made as follows: Batkovskiy, A.M.; Leonov, A.V.; Pronin, A.Yu.; Semenova, E.G.; Fomina, A.V.; Balashov, V.M. 2019. Sustainable development of Industry 4.0: the case of high-tech products system design, Entrepreneurship and Sustainability Issues 6(4): 1823-1838. http://doi.org/10.9770/jesi.2019.6.4(20)

JEL Classifications: O32, O33, C51

\section{Introduction}

Re-industrialization is a central component of the modern model of economic development, with the high-tech sector (Industry 4.0) being its basis, where priority is given to the digital industry, robotization, and the creation of innovative products (Romanova et al., 2017). The traditional way of creating any technical product involves the development and implementation of a number of design and regulatory documents. Timely development of these documents allows proceeding with the manufacture of the product. Although it was considered acceptable to have the development of a separate specific high-tech product with the best technical and economic characteristics as the end result of a traditional design scheme quite recently, at the present time such an approach is no longer relevant.

The feasibility of developing a product is closely linked to the tasks of creating a set of unified products, as well as the requirements of customers to their properties. Moreover, these requirements are formulated taking into account, on the one hand, the possibility of creating a scientific and technical reserve, and on the other, the possibility of establishing the optimal parameters of the structural and technological scheme of high-tech products. The consideration of the above-mentioned aspects is not sufficiently ensured by the traditional design methods used (Batkovskiy et al., 2016). Solving the problem of choosing the characteristics and the design and technological appearance of high-tech products is carried out by optimizing their parameters through a set of individual tasks. Often, the search for a solution is carried out in a heuristic way or, at best, on the basis of expert estimates. In this regard, the process of designing high-tech products needed to be allocated into a separate type the system design.

For the above purpose, the article consistently addresses the following issues: the principle of consistency and the formal logic of its use; an integrated model of system design, which includes the stages of engineering design and process design and a method for evaluating the effectiveness of unification at these stages; an algorithm for the practical implementation of an integrated model and proposals for its use in the creation of high-tech products. The practical application of the proposed tool will significantly reduce the cost of creating, manufacturing and operating high-tech products and also let obtain the structure of production with balanced efficiency and cost.

\section{Literature review}

The results of the analysis showed that the problems associated with the design of high-tech products have been studied quite extensively by now (Sobolev, \& Solovev, 2017). Moreover, in many works, the process of designing high-tech products is considered as part of an emerging product lifecycle management system (Golosovskii et al., 2014). These and a number of other works highlighted the design features of high-tech products, including (Baikin, \& Stetsyuk, 2014; Astakhov et al., 2015): the need to justify the level of the most significant product characteristics; the formation of a variety of options for the functional construction of the designed products; conducting technical and economic assessments of the designed products.

A number of works in the field of designing high-tech products made it possible to establish that there is certain regularity in the process of implementing the stages of the project for creating high-tech products. It was revealed that the distribution of different stages of work can be represented as a logistic distribution (Sobolev, \& Solovev, 2017). Various aspects of a probabilistic description of the development process of technical products based on a 


\section{ENTREPRENEURSHIP AND SUSTAINABILITY ISSUES}

ISSN 2345-0282 (online) http://jssidoi.org/jesi/

2019 Volume 6 Number 4 (June)

http://doi.org/10.9770/jesi.2019.6.4(20)

logistic model are provided (Demchenko, 2014). The logistic model is currently presented as one of the main regularities of the economic performance of high-tech products (Kaluzhskii, 2014). This distribution is often observed in the economy, production, and technology. Optimization models of economic performance in the conditions of uncertainty and risk, including methodological issues of problem statement and mathematical methods for solving and analyzing them, are considered (Shilova, 2014). Some scientists have touched on the problem of optimizing the research and development strategy in the field of new technologies. The questions of self-organization of economic performance models, the method of inductive self-organization, in particular, are researched. The works of scientists in which the trends in the development of CALS technologies in the production of various products are investigated (Alieva, 2017) are of outstanding interest; a dynamic model of quality management of product design in mechanical engineering (Panov, \& Trofimova, 2017); prospects for the use of mathematical modeling and digital design in ensuring product life cycle management (Tikhonov, \& Sazonov, 2018); methodological issues of developing strategies for the promotion of high-tech products (Goraeva, 2015); approaches to evaluating the effectiveness of investment in innovative projects (Vilenskiy et al., 2015).

However, despite the wide range of individual issues studied in the field of design, the system methodology for designing high-tech products is not sufficiently developed. The issues related to the substantiation of the optimal nomenclature and rational characteristics of high-tech products, as well as analysis and evaluation of the possibilities of unification, justification of the choice of rational options for the design-technological appearance of high-tech products (Kazanskaya, \& Palenova, 2015) remain unresolved. These circumstances have led to the need to improve the existing design tools for high-tech products.

The most significant contribution to solving the problems under consideration was made by the following researchers on the rationale for making rational decisions in the process of financing the development of high-tech products and new technologies (Calderon et al., 2015); methodical approaches to estimating and managing costs (Ely et al., 2014; Kamae et al., 2015; Hilkevics, Semakina, 2019); the use of a flexible development methodology to accelerate and improve the efficiency of innovative development by increasing the involvement and more efficient use of the creative potential of the team (Langdon et al., 2014); analysis of the patterns of innovation development and the strength of its influence on the activities of companies through the phenomena of "disruptive innovations" and "closing" technologies (Christensen, \& Clayton, 2016); The impact of risk management on the cost of a high-tech product development project was considered (Allen et al., 2015; Harris et al., 2017; Dubrovsky et al., 2011). The approaches to assessing the effectiveness of innovative projects in the field of high technologies with linguistic variables (Vlasov et al. 2017, 2018) were proposed.

The analysis showed that the main limitations in the use of these approaches are: industry-specific limitations; the need to adapt to different economic realities; orientation to some single factor in the creation of high-tech products and their market promotion, difficulties in obtaining source data, etc. (Bessant et al., 2015). These restrictions significantly complicate the comprehensive assessment of the possibility of implementing projects to create high-tech products within a given time, especially in risk, in relation to Russian enterprises as well (Batkovskiy et al., 2015). Thus, the toolkit and the design models for high-tech products have not been adequately considered from a system perspective.

\section{Methods}

\subsection{The principle of consistency in the design of high-tech products}

The complexity and multiplicity of the task of the system design of high-tech products required the creation of uniform methodological foundations. The introduction of the principle of consistency required an appeal to the 
hierarchical procedures for solving problems, using a set of uncoordinated criteria, which objectively led to the emergence of a number of problems.

1. Linking targets for all levels of high-tech products. In a generalized form, the model of gradual creation of high-tech products should be presented as the following:

$$
S=\left\{\begin{array}{l}
f_{1}: S \rightarrow S_{21} \\
f_{2}: S \rightarrow S_{32} \\
\cdots \\
f_{N-1}: S \rightarrow S_{N, N-1} \\
f_{N}: S \rightarrow S^{*}
\end{array},\right.
$$

where $S^{*}$ is the area of global targets; $S_{21}$ - the scope of targets formulated in the second stage of creating hightech products for the first one; $S_{32}$ - the scope of targets formulated in the third stage for the second; $S_{N, N-1}-$ the scope of targets formulated at the $N$-th stage for the $N-1$ st stage.

2. The next problem of introducing the principle of consistency is related to the fact that the indicators used in the feasibility study relate to different subject areas and have a different physical nature, reliability, and methods of assessment.

3. Estimation of cost indicators presents severe difficulties associated with identifying a multitude of analytical dependencies in various economic conditions.

The following algorithm is proposed for solving the problems considered. First, a set of indicators $(Q)$ is introduced, reflecting the state of high-tech products at various stages of their creation, defined at the time point $t$ :

$$
Q\left(R_{u}\right)=\left\{q_{i}^{t}\right\}, i=1, \ldots, M, \quad t=1, \ldots, T,
$$

where $R_{u}$ is an indicator of the level of resource support for the creation of high-tech products; $q_{i}^{t}-$ the value of the $i$-th indicator at the $t$-th point in time.

The required formation of the appearance of high-tech products during the budget period can be presented as its planned development pathway. For this set, $Q$ and $S$ must be one-to-one (each element $q_{i}^{t}$ of the set $\mathrm{Q}$ corresponds to a certain element $s$ of the set $S$ ).

As an indicator of the effectiveness of the development of high-tech products, it is advisable to take the degree of its state approaching the required appearance as:

$$
W(R)=Q_{m p}-Q(R),
$$

where $Q_{m p}=\left\{q_{m p i}^{t}\right\}$ is a set of indicators describing the parameters of the desired appearance of high-tech products to a specific point in time; $Q=\left\{q_{i}^{t}\right\}$ - a set of indicators describing the achieved appearance of high-tech products to a specific point in time.

Considering the above, the generalized indicator will look like: 


$$
W(R)=\left|\begin{array}{ccc}
\Delta w_{1}^{1}=q_{m p 1}^{1}-q_{1}^{1} & \ldots & \Delta w_{1}^{T}=q_{m p 1}^{T}-q_{1}^{T} \\
\ldots & \ldots & \ldots \\
\Delta w_{M}^{1}=q_{m p M}^{1}-q_{M}^{1} & \ldots & \Delta w_{M}^{T}=q_{m p M}^{T}-q_{M}^{T}
\end{array}\right| .
$$

In turn, the size of the deviation of each indicator $\left(\Delta w_{i}^{t}\right)$, which characterizes the appearance of high-tech products, depends on the level of support $\left(r_{i}^{t}\right)$ for the measures. The development level of high-tech products depends on the level of resource provision:

$$
W\left(R_{u}\right)=\left\{\Delta w_{i}^{t}=q_{m p i}^{t}-q_{i}^{t}\left(r_{i}^{t}\right)\right\}=Q_{m p}-Q_{t},
$$

where $r_{i}^{t}$ is the level of resource support for the $i$-th aspect of the operation of high-tech products in the $t$-th year; $R_{u}=\sum_{t=1}^{T} \sum_{i=1}^{M} r_{i}^{t} ; Q_{m p}=\left\{q_{m p i}^{t}\right\}-$ a set of indicators characterizing the desired appearance of high-tech products by the time $t ; Q_{t}=\left\{q_{i}^{t}\right\}$ - a set of indicators characterizing the achieved appearance of high-tech products by the time $t$.

The formulated provisions make it possible to determine the influence of the principle of consistency on the creation of high-tech products as an insurance of the minimum deviation of the achieved technical appearance of the product from the required one at different points of time with appropriate resource support. The introduction of the principle of consistency can minimize the $V\left(R_{u}\right)$ function describing the number of indicators of the appearance of high-tech products that have exceeded the permissible levels of values. Given the above, the function will take the following form:

$$
V\left(R_{u}\right)=\sum_{t=1}^{T} \sum_{i=1}^{M}\left(g_{i} \cdot w_{i t}^{o n}\left(r_{i}^{t}\right)\right) \rightarrow \min _{r}
$$

where $V\left(R_{u}\right)$ is the function of changing the size of the effect from the level of resource provision $R_{u}$ when introducing the principle of consistency; $R_{u}=\sum_{i=1}^{T} \sum_{i=1}^{M} r_{i}^{t}$ - the total cost of creating high-tech products within the planned period; $g_{i}$ is the weight of the $i$-th parameter in terms of describing the appearance of high-tech products $\sum_{i=1}^{M} g_{i}=1$

It is advisable to calculate the critical deviation of the $i$-th parameter at the $t$-th moment of time using the following formula:

$$
w_{i t}^{o n}\left(r_{i}^{t}\right)=\left\{\begin{array}{l}
1, \Delta w_{i}^{t}<\Delta w_{i d o p}^{t} \\
0, \Delta w_{i}^{t}>\Delta w_{i d o p}^{t}
\end{array} \text { at } C \leq L=f\left(S, \Delta w_{i}^{t}\right),\right.
$$

where $\mathrm{C}$ is the total cost of creating high-tech products in the planning period; $L$-appropriations limits; $\Delta w_{\text {idop }}^{t}-$ tolerance of the $i$-th indicator of the appearance of high-tech products.

In this case, the elements of the $\Delta w_{i}^{t}=q_{m p i}^{t}-q_{i}^{t}$ matrix become controlled parameters. With the known dependencies $\Delta w_{i}^{t}=F\left(r_{i}^{t}\right)$, the solution of the problem can be simplified, since it is possible to determine the values of the indicator describing the development trends of high-tech products $(\mathrm{W})$ at various levels of resource provision. 


\subsection{Design model}

In order to formalize the tasks of system design and sound choice of characteristics, the authors will present the entire set of high-tech products with the following set:

$$
N_{V T P}=\left\{N_{1}, N_{2}, \ldots, N_{k}\right\}_{O P T},
$$

where $N_{1}, N_{2}, \ldots, N_{k}$ are subsets (types) of high-tech products.

The optimal set of articles of high-tech products of the (8) form should take into account the needs of various customers, the purposes and objectives of the operation of high-tech products in various economic conditions. The described task is advisable to be completed in several stages. An integrated model of high-tech system design is shown in Figure 1.

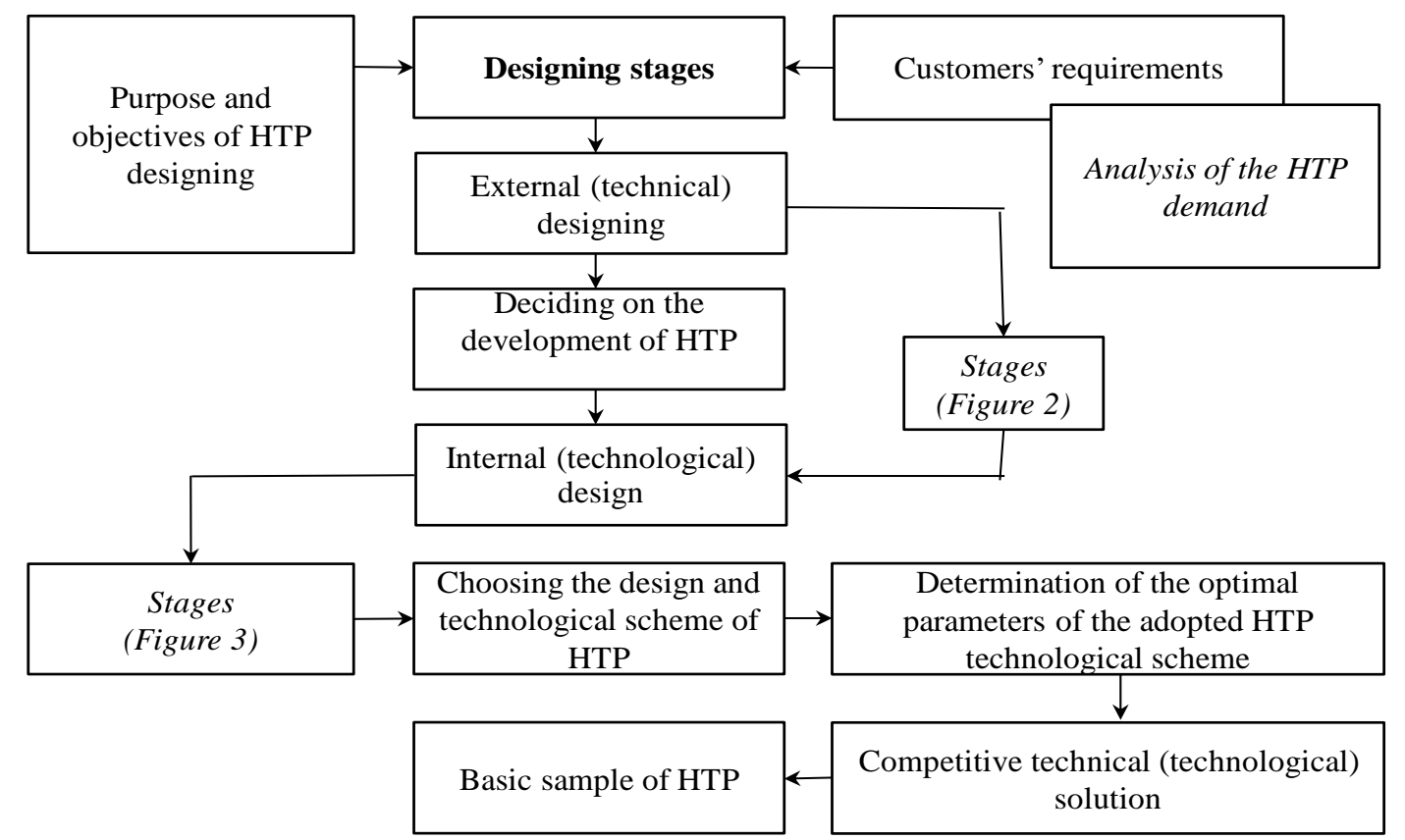

HTP - high-tech products

Fig. 1. Model of high-tech products system design

The practice of designing high-tech products shows that the degree of contribution of each stage to the overall result (as well as the value of the stages) increases from the final stage to the initial one (Sobolev, \& Solovev, 2017). This pattern is characteristic of both engineering and process design. Further, the contents of the engineering (Figure 2) and process (Figure 3) design stages are considered. 


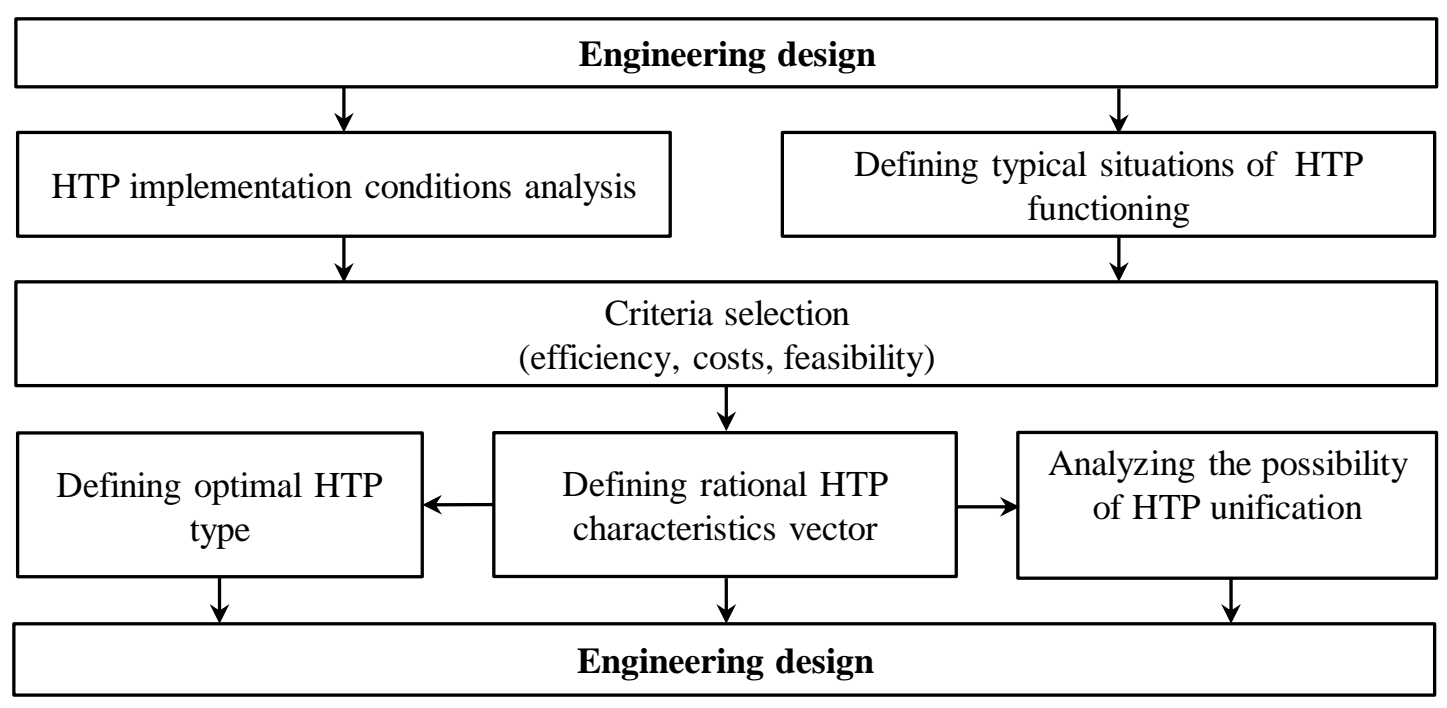

Fig. 2. Stages of high-tech products engineering design

Based on the needs of various customers of high-tech products and on the basis of the analysis of possible intersections of $N_{1}, N_{2}, \ldots, N_{k}$ subsets, an optimal (minimum) type of products created in the course of research and development work is determined:

$$
N_{V T R} \cap\left\{N_{1(1)}, N_{2(2)}, \ldots, N_{k(l)}\right\},
$$

where $N_{1(1)}, N_{2(2)}, \ldots, N_{k(l)}$ are the subsets of high-tech products, developed in the interests of various customers.

In this case, the possibility of unification of the products under development is analyzed. The implementation of such a possibility requires an intersection (9) and the preconditions of the following associations:

$$
\left\{n_{1}, n_{2}, \ldots, n_{k}\right\} \in N_{V T P(1)} \cup\left\{n_{1}, n_{2}, \ldots, n_{k}\right\} \in N_{V T P(2)} \cup \ldots \cup\left\{n_{1}, n_{2}, \ldots, n_{k}\right\} \in N_{V T P(l)}
$$

when:

$$
\mid \begin{aligned}
& K\left(N_{V T P(1)}\right)-K\left(N_{V T P(2)}\right) \mid \leq K_{d o p} \\
& K\left(N_{V T P(l-1)}\right)-K\left(N_{V T P(l)}\right) \mid \leq K_{d o p}
\end{aligned}
$$

where $n_{1}, n_{2}, \ldots, n_{k}$ are the elements of the subsets $N_{1}, N_{2}, \ldots, N_{k}$, respectively; $K$ is the optimal solution for every $N_{V T P(l)} ; K_{d o p}-$ permissible deviation from the optimal solution.

The choice of the rational characteristics of high-tech products may be represented as a process of suboptimization of the system (8) subject to conditions (9), (10) and (11). The procedure for selecting rational characteristics should be reduced to solving the problem of matching the elements to their associations, which can be represented in the following form:

$$
\begin{aligned}
& n_{1} \in N_{1} ; n_{2} \in N_{2} ; \ldots n_{l} \in N_{l} \\
& \cup\left(n_{1} ; n_{2} ; \ldots n_{l}\right)_{\max }=\max K
\end{aligned}
$$

Based on a constructive analysis of a sample of high-tech products, subsets of alternative technical solutions are formed: 


$$
A_{1}^{*} \cup\left(n_{1}^{*} ; n_{1}^{*} ; \ldots n_{l}^{*}\right)=K_{z a d},
$$

where $n_{1}^{*} ; n_{1}^{*} ; \ldots n_{l}^{*}$ are the elements forming alternative technical solutions $A_{1}^{*}$; some given criterion level $K_{z a d}$.

The formed subsets of alternative technical solutions (13) provide the basis for the formulation of the problem of synthesizing the design and technological scheme of a high-tech product. The essence of this task consists in the formation of variants of elements combination under the condition of their existence in various constraints, under which a certain specified level of the criterion $K_{z a d}$ (Esev et al., 2014) is provided. The task of synthesizing the design and technological scheme of a high-tech product is solved at the stages of process design.

The purpose of process design is the synergistic combination of various functional-technological elements (units) into a single scheme (Garina et al., 2017). This procedure contains the following as unknown parameters: types and number of functional elements (units), their level of development, communication between elements (units) to achieve the required values of the final product characteristics (Kazakova, \& Saveleva, 2014).

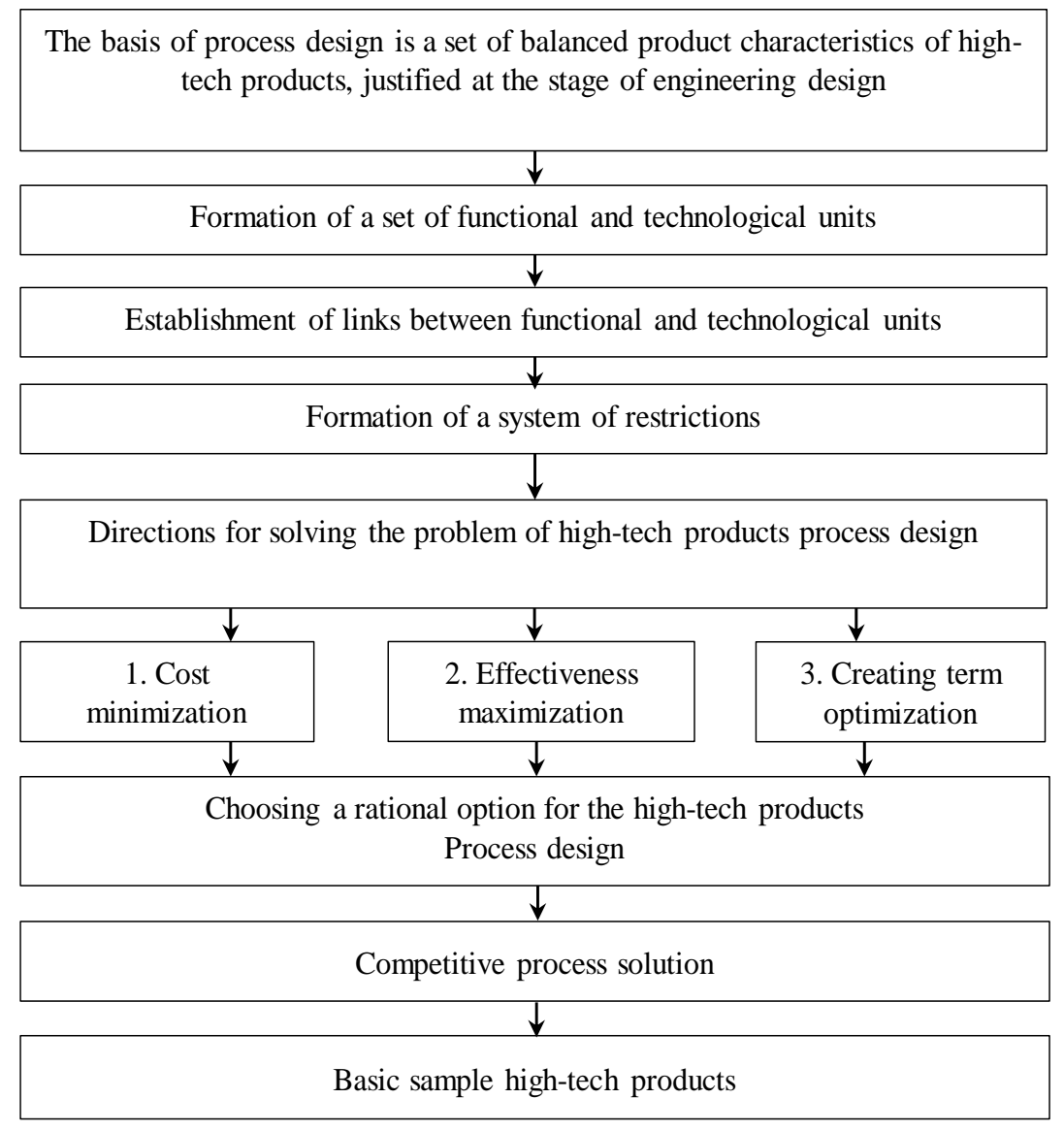

Fig. 3. Stages of high-tech products process design

Within the framework of process design, additional requirements are imposed on functional-technological (elements) units, such as: standardization, unification of elements; terms of the application of borrowed elements of a similar or another functional purpose (Skhirtladze et al., 2015). 
When developing high-tech products, special attention is paid to measures for the unification of components (Tretiakov, 2014). In this case, an assessment of the level of unification is usually carried out on the basis of a well-known approach using particular unification indicators (Borisov, \& Borisov, 2016).

As part of this study, a new method for assessing the level of unification has been proposed, based on a generalizing measure of the unification effectiveness. It is assumed that this ratio shows the change in the efficiency of the designed piece of high-tech products relative to some basic product at an equal level of costs for the performance of any task in their functional purpose. This ratio is determined by the following dependency:

$$
K_{e}=\frac{P^{p}}{P^{b}}, \quad \text { with } C^{p}=C^{b},
$$

where $C^{p}, C^{b}$ are the costs of performing the task in its functional purpose by the designed and by the basic piece of high-tech products, respectively; $P^{p}, P^{b}$ are the probabilities of accomplishing the task by the designed and basic articles of high-tech products, respectively.

In addition, it is assumed that the creation of high-tech products includes the development and production of their component parts. The task of determining the cost of manufacturing high-tech products is more complex. In this regard, it is assumed that only a certain percentage of consumers from their total number will be provided with developed high-tech products and in accordance with the standard membership of high-tech products in order to estimate the approximate level of production costs.

Based on this approach, the assessment of the level of product unification of high-tech products is carried out according to the following:

$$
K_{u}=\frac{\sum_{p=1}^{k} C_{p}^{u}-\sum_{q=1}^{l} \Delta N_{q}^{u} \cdot C_{q}^{u}}{\sum_{p=1}^{k} C_{p}^{o}}
$$

where $C_{p}^{u}, C_{p}^{o}$ are the costs of the $p$-th stage of designing a unified and non-unified versions of high-tech products, respectively; $\Delta N_{q}^{u}$ is a possible increase in production volumes for the considered period of time of the $q$-th standardized component (element) of a high-tech product; $C_{q}^{u}$ is the profit from the use of $q$-th unified component (element).

Taking into account the duration of the life cycle of a high-tech product and the formula (15) for the $q$-th unified component (element), it is advisable to use the following expression:

$$
K_{u}=\frac{C_{q}^{u}}{C_{q}^{0}}\left(1-\frac{\Delta N_{q}^{u}}{N_{q}^{o}}\right),
$$

which allows formula (14) to be expressed as:

$$
K_{e}=F\left(K_{u}, \alpha_{q}^{u}, \beta^{o}\right),
$$

where $\alpha_{q}^{u}, \beta^{o}$ are the generalized characteristics of non-unified and unified components (elements); $N_{q}^{o}$ is the total volume of production of the $q$-th component (element) of a high-tech product (as the sum of standardized and non-standardized components) for the considered period of time.

According to expression (17), there is a close relationship between the $K_{e}$ efficiency coefficient and the unification factor $K_{y}$, which should be taken into account when choosing a rational option for the structural and technological scheme of a high-tech product. 
Taking the considered features of engineering and process design into account, as well as evaluating the effectiveness of unification measures, an algorithm for the practical use of an integrated model for system design of high-tech products is proposed (Figure 4).

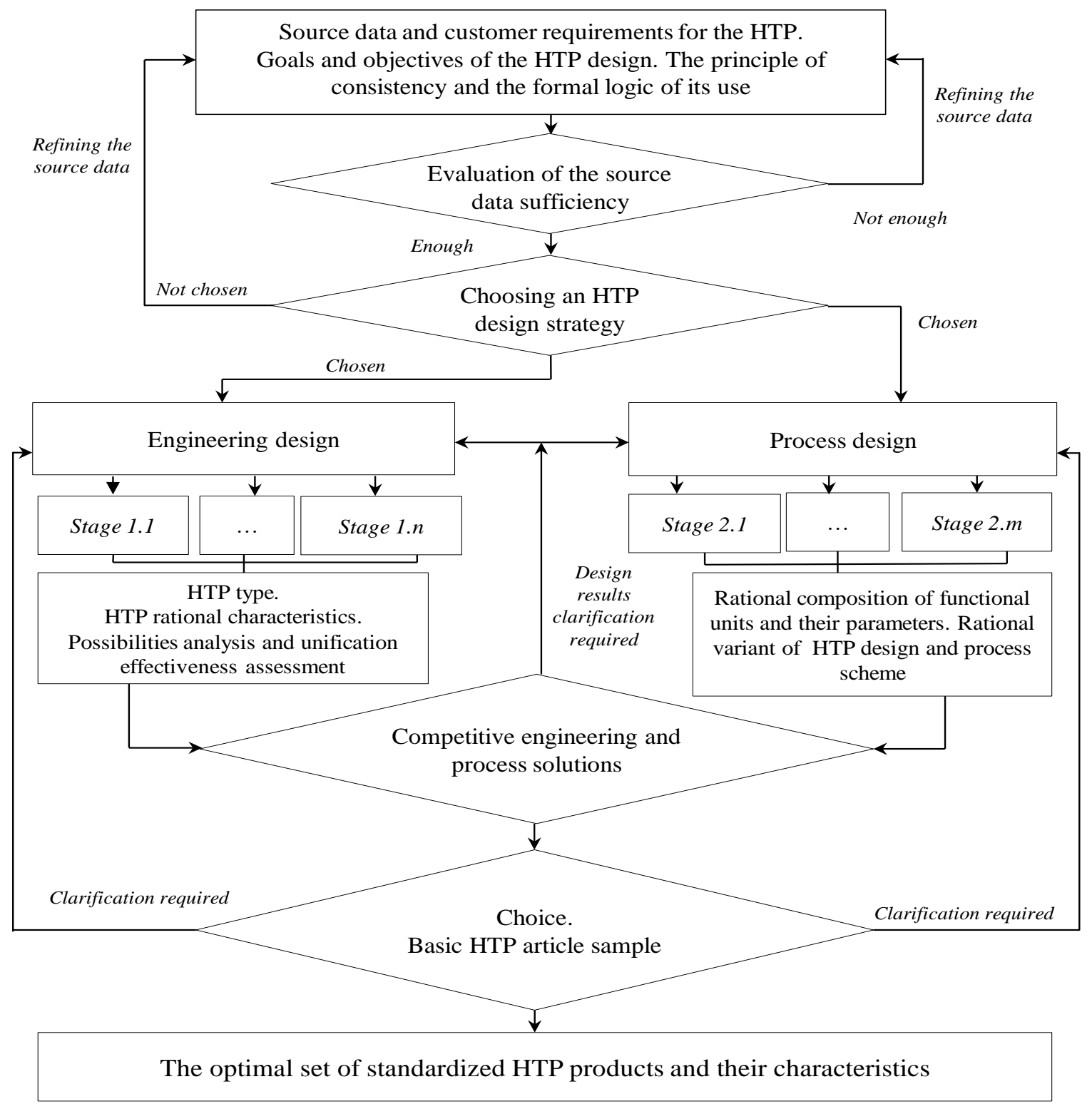

Fig. 4. Practical use algorithm for the integrated model of the high-tech products system design

A basic sample of a high-tech product and an optimal combination of such products are developed based on the choice of competitive engineering and process solutions. Thus, the proposed integrated model is aimed at justifying the required values of the designed products indicators and can be widely used in various sectors of the economy. 


\section{Results and Discussion}

On the basis of the reviewed methodology of engineering design, it is possible to substantiate on a scientific basis the constructive-technological appearance of promising high-tech products, including: moving from a balanced system of requirements for high-tech products to a specific composition of functional-technological units, i.e. determine their rational composition in the designed high-tech product. This task is formulated using the complex "efficiency - cost - feasibility" criterion in three variants of the problem statement: cost minimization; efficiency maximization; optimization of the timing of the creation of high-tech products.

System design is an effective methodological toolkit for optimizing efforts and resources for the development and manufacture of high-tech products while meeting the specified requirements for their properties and efficiency. The demand for system design is largely ensured by the integrated implementation of the principle of consistency in the formation of the system structure of high-tech products and of the appearance of specific items of high-tech products. The developed methodological toolkit should be used in planning agencies to assess the capabilities of design organizations and enterprises in executing orders for the creation of high-tech products.

As the practice approbation of the use of the developed toolkit, the authors consider a hypothetical high-tech product, the design of which is supposed to be carried out using one of 5 competing options (Table 1).

Table 1. Options for constructing a sample of high-tech products

\begin{tabular}{|l|r|r|r|r|r|}
\hline $\begin{array}{c}\text { Production sample } \\
\text { design options }\end{array}$ & $\begin{array}{c}\text { Indicator 1 } \\
(\mathrm{w}=0.15)\end{array}$ & $\begin{array}{c}\text { Indicator 2 } \\
(\mathrm{w}=0.25)\end{array}$ & $\begin{array}{c}\text { Indicator 3 } \\
(\mathrm{w}=0.1)\end{array}$ & $\begin{array}{c}\text { Unification coefficient } \\
(\mathrm{w}=0.3)\end{array}$ & $\begin{array}{c}\text { Price } \\
(\mathrm{w}=0.2)\end{array}$ \\
\hline Option 1 & 79 & 41 & 49 & 49 & 127 \\
\hline Option 2 & 84 & 19 & 34 & 44 & 140 \\
\hline Option 3 & 94 & 80 & 83 & 76 & 115 \\
\hline Option 4 & 109 & 58 & 74 & 49 & 130 \\
\hline Option 5 & 89 & 49 & 59 & 19 & 132 \\
\hline Base option & 100 & 75 & 90 & 70 & 200 \\
\hline
\end{tabular}

Within the framework of the task set, it is necessary to choose such an option for constructing a projected sample of high-tech products that is closest to the base variant. With the use of the developed toolkit, further technical and economic analysis of options for constructing competing samples of high-tech products is carried out. In order to do this, the degree of approximation of the indicators for constructing samples of high-tech products to the indicators of the base sample is calculated. The results of the calculations are shown in Table 2.

Table 2. Results of the calculation of the degree of approximation of the indicators of options for constructing samples of high-tech products to the indicators of the base sample

\begin{tabular}{|l|r|r|r|r|r|}
\hline \multirow{2}{*}{$\begin{array}{c}\text { Production sample design } \\
\text { variants }\end{array}$} & \multicolumn{5}{|c|}{ Relative value } \\
\cline { 2 - 7 } & $\begin{array}{c}\text { Indicator 1 } \\
(\mathrm{w}=0.15)\end{array}$ & $\begin{array}{c}\text { Indicator 2 } \\
(\mathrm{w}=0.25)\end{array}$ & $\begin{array}{c}\text { Indicator 3 } \\
(\mathrm{w}=0.1)\end{array}$ & $\begin{array}{c}\text { Unification coefficient } \\
(\mathrm{w}=0.3)\end{array}$ & $\begin{array}{c}\text { Price } \\
(\mathrm{w}=0.2)\end{array}$ \\
\hline Option 1 & 0.21 & 0.45 & 0.46 & 0.30 & 0.06 \\
\hline Option 2 & 0.16 & 0.75 & 0.62 & 0.37 & 0.17 \\
\hline Option 3 & 0.06 & 0.07 & 0.08 & 0.09 & 0.04 \\
\hline Option 4 & 0.09 & 0.23 & 0.18 & 0.30 & 0.08 \\
\hline Option 5 & 0.11 & 0.35 & 0.34 & 0.73 & 0.10 \\
\hline Base option & 0 & 0 & 0 & 0 & 0 \\
\hline
\end{tabular}

In order to conduct a feasibility analysis of options for constructing competing samples of high-tech products based on the data in Table 2, a petal diagram is constructed (Figure 5). 


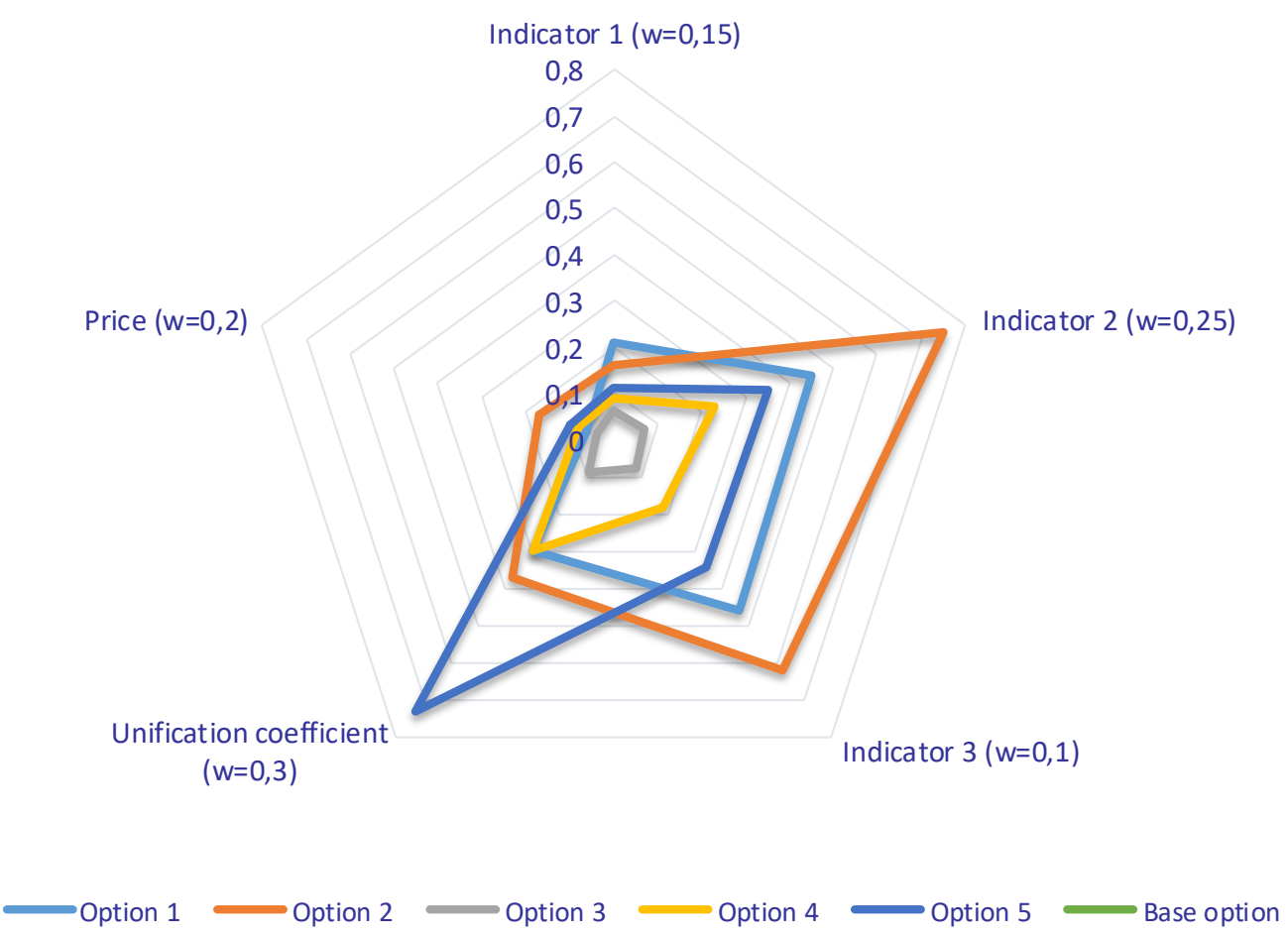

Fig. 5. Petal diagram characterizing the results of the feasibility analysis of options for constructing competing samples of high-tech products

Further comes the analysis of the results obtained using the ideal point method. It is apparent from Figure 5 that the closest to the basic variant (by all indicators) is option 3; therefore, it is advisable to design an advanced sample of high-tech products according to this variant. The remaining construction options have worse performance and require large resources to implement their design.

In general, the use of the system design methodical toolkit allows reducing the resource costs for the creation and manufacture of high-tech products and obtaining a balanced structure of the baseline items of high-tech products.

\section{Conclusions}

In modern scientific research, the designing of high-tech products is considered mainly in relation to individual products and much less often as the design of a set of high-tech products to meet the needs of different customers and be used in different operating conditions. Even less often, when designing high-tech products, measures to unify the component parts and elements of products are considered. That is why in this paper it was necessary to isolate and investigate from a system standpoint the designing of high-tech products with specified properties as part of a lifecycle management system.

The study found out that the system design of high-tech products is a methodology of structural-parametric synthesis. Parametric synthesis consists in determining the optimal dynamic parameters of the design and technological scheme of a high-tech product based on forming an acceptable set of alternative high-tech products and the choice of the dominant technological solution. Structural synthesis involves the development of a set of high-tech products, taking into account the environment, the conditions of operation of high-tech products, the requirements for them and the new technical solutions. 


\section{ENTREPRENEURSHIP AND SUSTAINABILITY ISSUES}

ISSN 2345-0282 (online) http://jssidoi.org/jesi/

2019 Volume 6 Number 4 (June)

http://doi.org/10.9770/jesi.2019.6.4(20)

As a result, a methodical toolkit for system design of high-tech products has been developed. The main elements of the developed model are: stages of engineering design; stages of process design; method of evaluating the unification effectiveness, suitable for use at both intraspecific and trans-species levels; and an algorithm for the practical use of an integrated model and proposals for its use at the stages of high-tech products creation.

The developed toolkit is advisable to be used in planning units in order to assess the capabilities of design organizations and enterprises in executing orders for the creation of high-tech products. Further improvement of the system design methodology should be aimed at achieving minimum costs or maximum efficiency at specified costs, taking into account the possibilities of unification in the design of high-tech products.

\section{Aknowledgements}

The study was carried out with the financial support of the Russian Foundation for Basic Research in the framework of the research project No. 18-00-00012 (18-00-0008) COMFI.

\section{References:}

Alieva, E.V. (2017). Cals-Technologies, Implementation of Case-Technologies in Production. NovaInfo, 58(5), 61-68. Retrieved March 19, 2019 from https://novainfo.ru/article/10822

Allen, M., Carpenter, C., Hutchins, M., \& Jones, G. (2015). Impact of Risk Management on Project Cost: An Industry Comparison. Journal of Information Technology \& Economic Development, 6(2), 1-19.

Astakhov, S.A., Shiryaev, A.N., \& Vorobev, A.A. (2015). Organization of Process Management of the Life Cycle of Products of Highly Specialized Enterprises. Trends and Management, 4, 423-432. https://doi.org/10.7256/2307-9118.2015.4.16086

Baikin, V.A., \& Stetsyuk, A.N. (2015). Formalization of Technological Procedures for Monitoring the Life Cycle of a Complex Engineering System. Software Systems and Computational Methods, 1, 52-58. https://doi.org/10.7256/2305-6061.2015.1.14407

Batkovskiy, A.M., Konovalova, A.V., Semenova, E.G., Trofimets, V.Ya., \& Fomina, A.V. (2015). Risks of Development and Implementation of Innovative Projects. Mediterranean Journal of Social Sciences, 6(4), S4, $243-253$. https://doi.org/10.5901/mjss.2015.v6n4s4p243

Batkovskiy, A.M., Semenova, E.G., Fomina, A.V., Khrustalev, E.Iu., \& Khrustalev, O.E. (2016). The Methodology and Mathematical Tools to Assess and Mitigate the Risk of Creating High-Tech Products. Indian Journal of Science and Technology, 9(27), 242-252. https://doi.org/10.17485/ijst/2016/v9i28/97659

Bertoni, F., Croce, A., \& Guerini, M. (2015). Venture Capital and the Investment Curve of Young High-Tech Companies. Journal of Corporate Finance, 35, 159-176. https://doi.org/10.1016/j.jcorpfin.2015.08.012

Bessant, J., Trifilova, A., \& Rush, H. (2015). Crisis-Driven Innovation: The Case of Humanitarian Innovation. International Journal of Innovation Management, 19(06). https://doi.org/10.1142/S1363919615400149

Borisov, V.M., \& Borisov, S.V. (2016). Assessment of the Level of Standardization and Unification of Engineering Products. Bulletin of Technological University, 19(3), 93-94.

Calderon, M., Salvatierra, O.A., \& Roording, R. (2015). The New Technology Cost-Effectiveness Checklist: Introducing A Practical Guideline for the Selection of Health Technologies. Value in Health, 18(7), A569. DOI: http://dx.doi.org/10.1016/j.jval.2015.09.1871

Christensen, A., \& Clayton, M. (2016). The Innovator's Dilemma (1st ed.). Boston, Mass.: Harvard Business Review Press. (p. 239). 


\section{ENTREPRENEURSHIP AND SUSTAINABILITY ISSUES}

ISSN 2345-0282 (online) http://jssidoi.org/jesi/

2019 Volume 6 Number 4 (June)

http://doi.org/10.9770/jesi.2019.6.4(20)

Demchenko, A.I. (2014). Process-Oriented Approaches to the Design and Modeling of Logistics Chains. Bulletin of the South Ural State University. Series: Economics and Management, 8(4), 169-178. Retrieved March 19, 2019 from https://vestnik.susu.ru/em/article/view/2890/273

Dubrovsky, V.Zh., Dulova, I.N., \& Kuzmin, E.A. (2011). Financial Risk Assessment in Cash Flow Forecasts for a Multi-Product Enterprise. Chelyabinsk State University Bulletin, 6(221), Economy, Issue 31, 100-107.

Ely, A., Van Zwanenberg, P., \& Stirling, A. (2014). Broadening out and Opening up Technology Assessment: Approaches to Enhance International Development, Co-Ordination and Democratisation. Research Policy, 43(3), 505-518. http://dx.doi.org/10.1016/j.respol.2013.09.004

Esev, A.A., Merezhko, A.N., \& Tkachuk, A.V. (2014). Technology Qualimetry Technical Level of Complex Systems. Bulletin of Computer and Information Technology, 7(121), 28-34. https://doi.org/10.14489/vkit.2014.07.pp.028-034

Garina, E.P., Kuznetsov, V.P., Romanovskaya, E.V., Lapaev, D.N., \& Yashin, S.N. (2017). Formation of the Production System Elements and R\&D Product Development Processes in the Early Stages of the Project. Journal of Applied Economic Sciences, 12(2(48), 538-542.

Golosovskii, M.S. (2014). The Model of the Life Cycle of Software Development in the Framework of Research. Automation. Modern Technologies, 1, 43-46.

Goraeva, T. (2015). Methods of Forming a Strategy for Promoting High-Tech Products. Science and Innovation. The National Academy of Sciences of the Republic of Belarus, 12(154), 52-56.

Harris, D., Villadsen, B., \& Koble, L. (2017). Risk and Return for Regulated Industries (1st ed.). Elsevier Academic Press. (p. 354).

Hilkevics, S., Semakina, V. (2019). The classification and comparison of business ratios analysis methods. Insights into Regional Development, 1(1): 48-57. https://doi.org/10.9770/ird.2019.1.1(4)

Kaluzhskii, M.L. (2014). Economic Dynamics: Institutions, Systems and Self-Organization. Economic Analysis: Theory and Practice, 5(356), 27-38.

Kamae, I., Sugimoto, T., \& Yamabe, K. (2015). Value-Based Pricing Scheme for New Technology in Consideration of Cost-Effectiveness Dominance to the Control. Value in Health, 18(7), A732. http://dx.doi.org/10.1016/j.jval.2015.09.2796

Kazakova, N.V., \& Saveleva, I.V. (2014). Enterprise Planning Based on a Synergistic Approach. Economy and Entrepreneurship, 1-2(42), 581-584.

Kazanskaya, G.N., \& Palenova, T.V. (2015). Standardization - the Basis of Product Quality. Economy and Entrepreneurship, 5-1(58), 846849.

Langdon, M., Ma, M., \& Wu, P.C. (2014). Agile Innovation: The Revolutionary Approach to Accelerate Success, Inspire Engagement, and Ignite Creativity. John Wiley \& Sons. (p. 400).

Panov, A.Yu., \& Trofimova, M.S. (2017). Dynamic Model of Quality Management for Designing Machine Tools. Bulletin of the Perm National Research Polytechnic University. Electrical Engineering, Information Technology, Control Systems, 24, 91-104.

Romanova, O.A., Korovin, G.B., \& Kuzmin, E.A. (2017). Analysis of the Development Prospects for the High-Tech Sector of the Economy in the Context of New Industrialization. Revista Espacios, 38(59), 25.

Shilova, A.A. (2014). Economic Dynamics: Research Methodology. NAUKA-RASTUDENT.RU: Electronic Scientific Journal, 3(03), 7-12. Retrieved March 19, 2019 from http://nauka-rastudent.ru/3/1244, https://doi.org/10.1016/j.jedc.2019.03.001

Skhirtladze, A.G., Skryabin, V.A., \& Zotov, E.V. (2015). Unification in the Design and Testing of Products of Engineering Production. Repairs. Recovery. Modernization, 1, 44-48.

Sobolev, A.A., \& Solovev, V.I. (2017). Life Cycle Management of Complex Systems in the Context of System Engineering. Innovations to Life, 2(21), 137-174. 


\section{ENTREPRENEURSHIP AND SUSTAINABILITY ISSUES}

ISSN 2345-0282 (online) http://jssidoi.org/jesi/

2019 Volume 6 Number 4 (June)

http://doi.org/10.9770/jesi.2019.6.4(20)

Tikhonov, A.I., \& Sazonov, A.A. (2018). Prospects for Using the Methods of Mathematical Modeling and Digital Design in Ensuring Product Life Cycle Management. Management and Business Administration, 3, 118-128.

Tretyakov, V.M. (2014). Evaluation of the Diversity of Components of Manufactured Products. Standards and Quality, 12, 34-36.

Vilenskiy, P.L., Livshits, V.N., \& Smolyak, S.A. (2015). Assessment of Investment Projects Efficiency. Theory and Practice. Moscow: Poli Print Service. (p. 1300).

Vlasov, A.I., Echeistov, V.V, Krivoshein, A.I., Shakhnov, V.A., Filin, S.S., \& Migalin, V.S. (2018). An Information System of Predictive Maintenance Analytical Support of Industrial Equipment. Journal of Applied Engineering Science, 16(4), 515-522. http://doi.org/10.5937/jaes16-18405

Vlasov, A.I., \& Demin, A.A. (2017). Visual Methods of Formalization of Knowledge in the Conditions of the Synchronous Technologies of System Engineering. In ACM International Conference Proceeding Series. http://doi.org/10.1145/3166094.3166098

Aleksandr M. BATKOVSKIY, Dr. Sci. (Economics), Senior Researcher, JSC “Central Research Institute of Economy, Management and Information Systems "Electronics", Moscow, Russian Federation. Research interests: economics of industry, management, production efficiency, sustainable systems.

ORCID ID: orcid.org/0000-0002-5145-5748

Aleksandr V. LEONOV, Dr. Sci. (Economics), Professor of the Department of management of high-tech enterprises, Moscow Aviation Institute (National Research University), Moscow, Russian Federation. Research interests: innovation, high-tech products, enterprise management.

ORCID ID: 0000-0001-8948-1311

Aleksey Yu. PRONIN, Cand. Sci. (Engineering), Assistant professor of the Department of management, MIREA - Russian Technological University, Moscow, Russian Federation. Research interests: technologies, high-tech products, industry analysis, management of high-tech enterprises, sustainable systems.

ORCID ID: 0000-0001-8947-3047

Elena G. SEMENOVA, Dr. Sci. (Engineering), Professor, Director of the Institute of Innovation and master basic training, SaintPetersburg State University of Aerospace Instrumentation, St. Petersburg, Russian Federation. Research interests: innovative activity, modeling, sustainable systems, management, applied mathematics.

ORCID ID: orcid.org/0000-0001-8312-4903

Alena V. FOMINA, Dr. Sci. (Economics), Assistant professor, JSC “Central Research Institute of Economy Management and Information Systems "Electronics", Moscow, Russian Federation. Research interests: regional economy, industrial economy, development strategies and restructuring, strategic planning, high-tech production structures, financial and economic planning, sustainable economic systems.

ORCID ID: orcid.org/0000-0002-5853-0309

Victor M. BALASHOV, Dr. Sci. (Engineering), Professor, JSC «Scientific and Production Enterpise "Radar MMS"», Saint-Petersburg, Russian Federation. Research interests: reengineering, enterprise economics, economic and mathematical modeling.

ORCID ID: orcid.org/0000-0003-4642-5701 
ENTREPRENEURSHIP AND SUSTAINABILITY ISSUES

ISSN 2345-0282 (online) http://jssidoi.org/jesi/

2019 Volume 6 Number 4 (June)

http://doi.org/10.9770/jesi.2019.6.4(20)

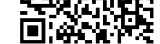

Register for an ORCID ID:

https://orcid.org/register

Copyright (C) 2019 by author(s) and VsI Entrepreneurship and Sustainability Center

This work is licensed under the Creative Commons Attribution International License (CC BY).

http://creativecommons.org/licenses/by/4.0/

c) (i) Open Access 